532.61

DOI 10.36910/6775-2313-5352-2021-18-2

Біліщук В.Б., Боднар Р.Т.

Івано-Франківський національний технічний університет нафти і газу

\title{
УДОСКОНАЛЕНИЙ МЕТОД ОБЕРТОВОЇ КРАПЛІ
}

В статті вказано особливості застосування водних розчинів поверхнево-активних речовин в газо- нафтовидобутку. Вказано визначальні параметри таких розчинів, які досліджують при виборі застосовуваних поверхнево-активних речовин. Здійснений аналіз відомих методик визначення міжфазного натягу методом обертової краплі показав можливість вдосконалення процееури розрахунку міжффазного натягу для ї̈ спрощення. В статті запропоновано вдосконалити методику розрахунку міжфазного натягу методом фіксованої обертової краплі із застосуванням рівняння Воннегута з коригуючим коефічієнтом. Значення коригуючого коефіцієнта було отримано із розрахунків контурів фіксованих обертових крапель, а також розрахунку міжфазного натягу із застосуванням формули Воннегута на основі розрахованих контурів. Встановлено, щуо коригуючий коефіцієнт можна представити як функиіональну залежність від відношення діаметра до довжини обертової краплі. Для перевірки такого зв'язку здійснювали розрахунок коефіцієнтів корелячії між коригуючим коефіцієнтом та розмірами обертової краплі. В ході експериментальної перевірки було підтверджено можливість використання розробленої методики для дослідження параметрів водних розчинів поверхнево-активних речовин з нафтопродуктами.

Ключеві слова: Рівняння Воннегута, міжфазний натяг, поверхнево-активна речовина, нафтопродукти.

\section{Постановка проблеми.}

Сфера використання поверхнево-активних (ПАР) речовин на даний час є досить широкою. Більшість галузей народного господарства країни використовують в своїх технологічних процесах ПАР або їх композиції. Зокрема, з метою збільшення об'ємів нафтогазовидобутку в Україні широко використовують водяні розчини ПАР, за допомогою яких здійснюється обробка привибійних зон пластів експлуатаційних і нагнітальних свердловин, а також підтримування пластових тисків на нафтових родовищах. До визначальних параметрів розчинів ПАР слід віднести такі: поверхневий натяг (на межі контакту рідкої і газоподібної фаз), міжфазний натяг (MH) (на межі контакту двох нерозчинних одна в одній рідких фаз) і крайовий кут змочування (на межі контакту трьох фаз). Тому актуальним $\epsilon$ застосування методик і вимірювальних приладів для оцінки показників розчинів ПАР у конкретних технологічних операціях [1] при виборі типів ПАР.

Аналіз останніх досліджень і публікацій.

Першим, хто запропонував використовувати метод обертової краплі для визначення МН був Б. Воннегут [2]. Суть методу полягає в наступному. Всередині рідини $\beta$ (рис. 1), що знаходиться в герметичній трубці, присутня крапля легшої рідини $\alpha$. Трубка з рідинами обертається навколо горизонтальної осі. За рахунок відцентрових сил важча рідина витісняється до периферії, а крапля легшої рідини - до осі обертання. Крапля легшої рідини приймає видовжену форму вздовж осі обертання. Даний процес проходить проти сил МН, які намагаються зробити краплю з меншою площею поверхні. В запропонованому методі МН визначають із такої залежності:

$$
\sigma=\frac{\Delta \rho \omega^{2} D^{3}}{32}
$$

де $\Delta \rho$ - різниця густин рідин; $\omega$ - швидкість обертання; $D$ - діаметр краплі.

Наступні роботи Прінсена, Дж. Слаттері, С. Чена, Р. Кісіля [3-5] були присвячені вдосконаленню методики розрахунку МН на основі вимірювання різних геометричних розмірів краплі, що зменшило похибку вимірювання МН.

В роботі [6] запропоновано методику, в якій крапля витискається через отвір в корку під час обертання і одним кінцем фіксується на вертикальній стінці (рис. 2). При цьому рідини обертаються з однаковою швидкістю і є можливість дослідження динамічного (змінного в часі) 
МН. Розрахунок МН грунтується на складній ітераційній процедурі розрахунку контуру обертової краплі на основі диференційних рівнянь.

$$
\frac{d \varphi}{d l_{c}}=K_{c}-\frac{x_{c}^{2}}{2}-\frac{\sin \varphi}{x_{c}}, \frac{d x_{c}}{d l_{c}}=\cos \varphi, \frac{d z_{c}}{d l_{c}}=\sin \varphi,
$$

де $x_{c}=x / c, z_{c}=z / c$ - безрозмірні координати точок контуру обертової краплі; $x, z$ - розмірні координати точок контуру обертової краплі; $c=\left(\sigma /\left(\Delta \rho \cdot \omega^{2}\right)\right)^{1 / 3}-$ обертова стала; $\Delta \rho-$ різниця густин рідин; $\omega$ - кутова швидкість обертання; $\sigma$ - міжфазний натяг на межі розділу двох рідин; $\varphi$ - кут між віссю обертання трубки та нормаллю, проведеною до контуру обертової краплі в точці з координатами $x_{c}, z_{c} ; K_{c}=K \cdot c, K_{c}, K$ - безрозмірна і розмірна кривизна поверхні обертової краплі у іiї вершині; $l_{c}=l / c, l_{c}, l-$ безрозмірна і розмірна довжина дуги меридіана профілю обертової краплі від її вершини.

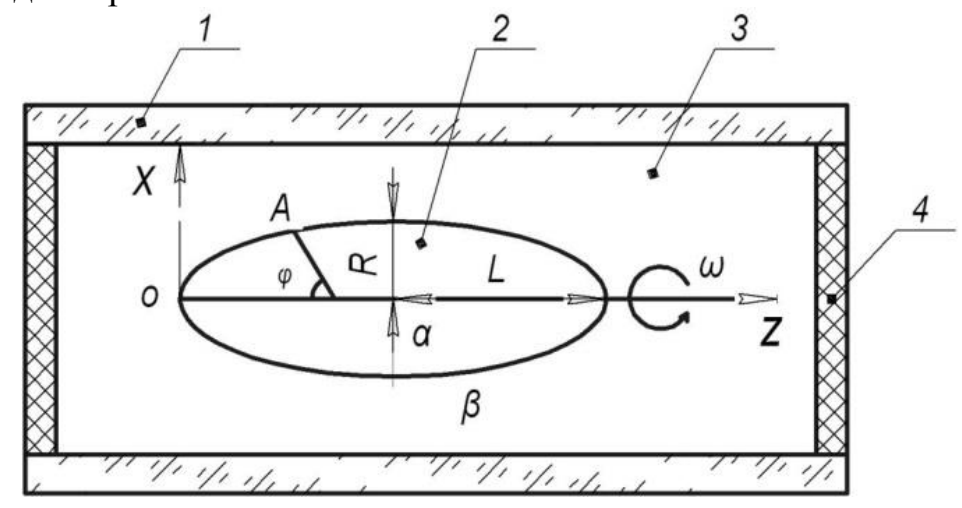

Рис. 1. Профіль краплі при обертанні навколо горизонтальної осі z 1 - скляна трубка; 2 - крапля легшої рідини; 3 - важча рідин; 4- корок

Розв'язок таких рівнянь можливий тільки числовими методами, наприклад Рунге-Кутта, потребує використання обчислювальної техніки, що є недоліком запропонованої методики в роботі [6].

\section{Постановка завдання.}

Метою даної роботи є розроблення методики визначення МН рідин, яка дозволить застосовувати рівняння (1) для фіксованої обертової краплі.

\section{Виклад матеріалів дослідження.}

Застосування рівняння (1) для розрахунку значення МН дозволить спростити процедуру визначення МН, так як відпаде необхідність здійснювати громіздкі багато разів повторювані ітераційні розрахунки координат точок контуру обертової краплі. В ході експериментальних досліджень було виявлено, що при наявності на контурі фіксованої обертової краплі частини, що має видовжену циліндричну форму формула (1) дає такий самий результат як і застосована ітераційна процедура. В інших випадках застосування рівняння (1) неможливе. Пропонується у вираз (1) добавити коефіцієнт $F$, який буде коригувати розраховане значення, так щоб воно відповідало дійсному. Цей коефіцієнт $F$ може бути представлений як функція параметрів краплі, які враховують в рівняннях (2), діаметра $D$ в певному січені і довжини $L_{\max }$ краплі: $F\left(x, z, l, K, D, L_{\max }\right)$. Рівняння (1) набуде вигляду

$$
\sigma=\frac{\Delta \rho \omega^{2} D^{3}}{32} \cdot F\left(x, z, l, K, D, L_{\max }\right) .
$$

Розглянемо вибір параметрів, який може бути використаний для розрахунку коефіцієнта $F$. Коефіцієнт $F$ можна визначати як залежність від різних параметрів краплі або їх поєднання. Очевидно зручно використовувати параметри, які легко визначаються в експерименті. Такими параметрами є діаметр $D$ i довжина краплі $L_{\max }$. Як було написано вище діаметр краплі може визначатись в будь-якому їі січенні, найзручніше було б визначати діаметр посередині профілю краплі (рис. 2).

Перевірку взаємозв'язку між $F$ і $D, L_{\max }$ здійснювали шляхом розрахунку коефіцієнта кореляції між ними. Для цього згідно виразів (2) розраховували розмірні контури обертової краплі з заданим МН $\sigma$. Для кожного контуру розраховували $\mathrm{MH} \sigma_{B}$ згідно (1) і коефіцієнт $F$ : 


$$
F=\frac{\sigma}{\sigma_{B}}
$$

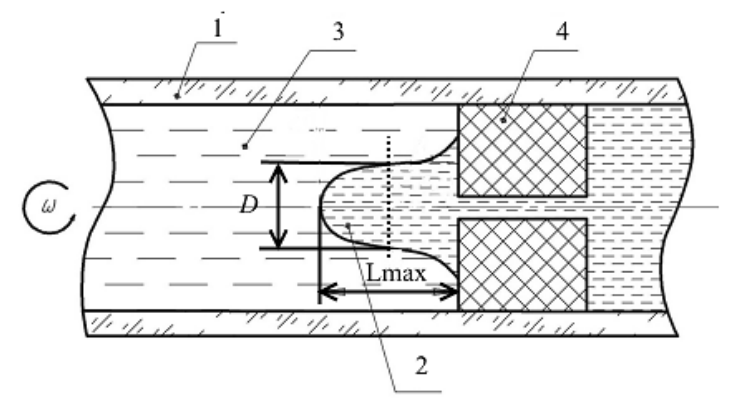

Рис. 2. Контур фіксованої обертової краплі

1 - скляна трубка; 2 - крапля легшої рідини; 3 - важча рідина; 4- корок з отвором

На основі розрахованих координат точок контурів обертових крапель визначали $L_{\text {max }}, D$ і коефіцієнти кореляції $C$ між $F$ і $L_{\max }$ : $\mathrm{C}_{F, L m a x}=-0,577$, а також $F$ і $D: \mathrm{C}_{F, D}=-0,157$. Отже застосування тільки одного параметра не дає можливості однозначного встановлення залежності між $F$ і розмірами краплі. В той же час було виявлено, що при застосуванні відношення $D / L_{\max }$ iснує корелійний зв'язок з $F$ : $C_{F, D / L \max }=0,962$. Отже $F$ може бути представлений як функція від $D / L_{\max }$.

Для знаходження залежності $F\left(D / L_{\max }\right)$ було розраховано їх значення для різних контурів (табл. 1). Як видно із таблиці для крапель з $D / L_{\max }<0,2$ (тобто довжина краплі має бути в 5 раз більшою за діаметр в середній частині) можливо використовувати формулу Воннегута (1), відносна методична похибка при цьому не перевищуватиме $0,2 \%$.

Таблиця 1.

Розраховані значення $F$ i $D / L_{\max }$

\begin{tabular}{|c|c|c|c|c|c|c|c|}
\hline$F$ & $D / L_{\max }$ & $F$ & $D / L_{\max }$ & $F$ & $D / L_{\max }$ & $F$ & $D / L_{\max }$ \\
\hline 1,001039 & 0,22196 & 1,002179 & 0,418705 & 1,035984 & 0,789224 & 1,415196 & 1,822904 \\
\hline 1,001007 & 0,236717 & 1,010066 & 0,594264 & 1,074951 & 0,978523 & 1,570379 & 2,12858 \\
\hline 1,00121 & 0,324853 & 1,035984 & 0,78922 & 1,169168 & 1,271022 & 1,757722 & 2,474972 \\
\hline 1,002179 & 0,418704 & 1,035984 & 0,789223 & 1,281753 & 1,542066 & 1,757728 & 2,474969 \\
\hline
\end{tabular}

Апроксимувавши дані в табл. 1 поліномами різного порядку, одержимо значення коефіцієнтів апроксимуючих поліномів і середнє геометричне суми квадратів різниць між даними табл. 1 і результатами апроксимації (табл. 2). Як видно із отриманих даних для апроксимації недоцільно використовувати поліноми вище 6-го порядку і нижче 3-го порядку.

Таблиця 2.

Результати апроксимації залежності $F\left(D / L_{\max }\right)$

\begin{tabular}{|c|c|c|c|c|c|c|}
\hline \multirow{2}{*}{ Коефіцієнт } & \multicolumn{7}{|c|}{ Степінь полінома } \\
\cline { 2 - 7 } & 1 & 2 & 3 & 4 & 5 & 6 \\
\hline$a_{0}$ & 0,82858 & 0,99518 & 1,0405 & 1,0262 & 0,99928 & 0,99841 \\
\hline$a_{1}$ & 0,34124 & $-0,048294$ & $-0,22504$ & $-0,14566$ & 0,039636 & 0,047135 \\
\hline$a_{2}$ & & 0,14597 & 0,31137 & 0,18604 & $-0,22496$ & $-0,24761$ \\
\hline$a_{3}$ & & & $-0,041732$ & 0,030536 & 0,41807 & 0,44965 \\
\hline$a_{4}$ & & & & $-0,013620$ & $-0,17501$ & $-0,19695$ \\
\hline$a_{5}$ & & & & & 0,024412 & 0,031778 \\
\hline$a_{6}$ & & & & & & $-0,00095047$ \\
\hline
\end{tabular}




\begin{tabular}{|l|l|l|l|l|l|l|}
\hline $\begin{array}{l}\text { Середнє } \\
\text { геометричне } \\
\text { суми } \\
\text { квадратів } \\
\text { різниць }\end{array}$ & 0,0697 & 0,0120 & 0,00276 & 0,00198 & 0,000423 & 0,000421 \\
\hline
\end{tabular}

Із врахування апроксимаційної залежності формулу (3) можна переписати у вигляді:

$$
\sigma=\frac{\Delta \rho \omega^{2} D^{3}}{32} \cdot \sum_{i} a_{i}\left(\frac{D}{L_{\max }}\right)^{i}
$$

\section{Обговорення результатів.}

Для експериментальної перевірки використовували $1 \%$ водний розчин ПАР стінолу і гас. В ході експерименту МН визначали методом Воннегута і розглянутим у статті. При використанні розробленого методу спеціально знижували частоту обертання трубки з рідинами так, щоб на краплі не утворювалась циліндрична частина. Частота обертів не перевищувала 2000 об/хв. Результати вимірювань МН продемонстровані в таблиці 2. Результати демонструють хорошу повторюваність значень МН, що підтверджує ефективність розробленого методу.

Слід обговорити деякі обмеження і застереження щодо застосування розробленої методики. В ході експерименту забезпечувалась умова повного змочування краплею рідини (гасом) стінки корку (фторопласт) при третій фазі - воді (чи водному розчину ПАР). Розрахунки із розв'язуванням рівнянь (2) також проводились для умов повного змочування. Таким чином в ході експериментальних досліджень був усунений один із параметрів, що впливає на результат - кут змочування. При дослідженні нафтопродуктів такі випадки переважають - в конструкції приладу використовують корки з фторопласту, які добре змочуються нафтопродуктами і гірше водними розчинами ПАР. При використанні інших матеріалів або досліджуваних рідин може не забезпечуватись умова повного змочування. В такому випадку необхідно розрахунки здійснювати із врахуванням кута змочування (який попередньо визначають).

Таблиця 2.

Результати визначення міжфазного натягу $1 \%$ водного розчину стінолу з гасом

\begin{tabular}{|c|c|c|}
\hline \multirow{2}{*}{$\begin{array}{r}\text { Номер } \\
\text { досліду }\end{array}$} & \multicolumn{2}{|c|}{ Міжфазний натяг, мН/м } \\
\hline & $\begin{array}{r}\text { Метод } \\
\text { Воннегута }\end{array}$ & $\begin{array}{l}\text { Запропонований } \\
\text { метод }\end{array}$ \\
\hline 1 & 0,2 & 0,198 \\
\hline 2 & 0,214 & 0,203 \\
\hline 3 & 0,217 & 0,228 \\
\hline
\end{tabular}

\section{Висновки.}

Запропонований метод не вимагає проведення великої кількості обрахунків теоретичних контурів фіксованих обертових крапель, що значно спрощує і полегшує проведення експериментів. При цьому зберігаються переваги методу описаного в [6] утворення краплі під час обертання рідин в гіростатичній рівновазі дозволяє визначати МН рідин 3 невеликою затримкою в часі (не більше 0,3 c), що можна використовувати для дослідження динамічного МН. Відсутність необхідності використання високих частот обертання трубки з рідинами спрощує процедуру проведення вимірювань і конструкцію приладу.

\section{Література}


1. Михайлюк В., Рудий М., Використання поверхнево-активних речовин в процесах нафтовидобутку на родовищах ВАТ"Укрнафта". - ПП „Галицька друкарня ПЛЮС”, 2009, 399 c.

2. Vonnegut B. Rotating Bubble Method for the Determination of Surface and Interface Tensions // Rev. Sci. Instr. - 1942.- V13, No1. - P. 6-9.

3. Princen H. M. Measurement Of Interfacial Tension From The Shape Of A Rotating Drop / H. M. Princen, I. Y. Z. Zia, S. G. Mason // J. Colloid Interface Sci. - 1967. - No 23. - P. 99-107.

4. Slattery J. C. Alternative solution for spinning drop interfacial tensio-meter / J. C. Slattery, J. D. Chen // J. Colloid Interface Sci. - 1978 - V64, No2 - P. 371-373.

5. Кісіль Р. І., Чеховський С. А. Удосконалена методика і прилад для вимірювання міжфазного натягу методом обертової краплі. Методи та прилади контролю якості. - 1999. No4. - C. 36-39.

6. Біліщук В. Б. Метрологічні дослідження вимірювання міжфазного натягу рідин методом обертової краплі. - 2020. - №4.- С. 22-28.

Билищук В. Б., Боднар Р. Т.

Ивано-Франковский национальный технический университет нефти и газа

\section{УСОВЕРШЕНСТВОВАННЫЙ МЕТОД ВРАЩАЮЩЕЙСЯ КАПЛИ}

В статье указано особенности применения водных растворов поверхностно-активных веществ в газ нефтедобычи. Указано определяющие параметры таких растворов, которые исследуют при выборе применяемых поверхностно-активных веществ. Проведенный анализ известных методик определения межфазного натяжения методом вращающейся капли показал возможность совериенствования прочедуры расчета межфазного натяжения для ее упрощения. В статье предложен усовершенствовать методику расчета межфазного натяжения методом фиксированной вращающейся капли с применением уравнения Воннегута c корректирующим коэффищиентом. Значения корректирующего коэффициента было получено по расчетам контуров фиксированных вращающихся капель, а также расчета межфазного натяжения с применением формулы Воннегута на основе рассчитанных контуров. Установлено, что корректирующий коэффициент можно представить как функииональную зависимость от отномения диаметра к длине вращающейся капли. Для проверки такой связи осуществляли расчет коэффициентов корреляции между корректирующим коэффициентом и размерами вращающейся капли. $B$ ходе экспериментальной проверки была подтверждена возможность использования разработанной методики для исследования параметров водных растворов поверхностно-активных веществ с нефтепродуктами.

Уравнение Воннегута, межфазное натяжение, поверхностно-активное вещество, нефтепродукты.

Bilishchuk V. B., Bodnar R. T.

Ivano-Frankivsk National Technical University of Oil and Gas

\section{ADVANCED METHOD OF ROTARY DROP}

The article indicates the features of the use of aqueous solutions of surfactants in gas and oil production. The defining parameters of such solutions which are investigated at a choice of the applied surfactants are specified. The analysis of the known methods for determining the interfacial tension by the rotating drop method showed the possibility of improving the procedure for calculating the interfacial tension to simplify it. In the article it is offered to improve a technique of calculation of an interfacial tension by a method of a fixed rotating drop with application of the equation of Vonnegut with a correction factor. The value of the correction factor was obtained from the calculations of the contours of the fixed rotating drops, as well as the calculation of the interfacial tension using the Vonnegut formula based on the calculated contours. It is established that the correction factor can be represented as a functional dependence on the ratio of diameter to the length of the rotating drop. To verify this relationship, the correlation coefficients between the correction factor and the size of the rotating drop were calculated. During the experimental test, the possibility of

(C) Біліщук В. Б., Боднар Р. Т. 
using the developed technique to study the parameters of aqueous solutions of surfactants with petroleum products was confirmed.

Vonnegut equation, interfacial tension, surfactant, petroleum products.

(C) Біліщук В. Б., Боднар Р. Т. 